\title{
Iduna contributes to the therapeutic effect of DHA in a cell and mouse model of traumatic brain injury via Wnt/MDM2 pathway
}

\author{
Xinyu Shi ${ }^{1^{*}}$, Fan Yang ${ }^{1^{\star}}$, Zhenyu Ge ${ }^{2^{\star}}$, Zongchun Tang ${ }^{1}$, Kunhu Zhang ${ }^{1}$, Bobo Chen ${ }^{1}$, Hongbin Wang ${ }^{1}$, Jian Hou ${ }^{3}$, \\ $\mathrm{Hu} \mathrm{Li}{ }^{1}$, Zheng Tang ${ }^{1}$ \\ ${ }^{1}$ Baoji High-tech Hospital, Baoji, Shaanxi, China, ${ }^{2}$ Baoji Central Hospital, Baoji, Shaanxi, China, ${ }^{3}$ Shanxi Provincial Corps Hospital \\ of the CAPF, Taiyuan, Shanxi, China \\ *These authors contributed equally to this work.
}

\begin{abstract}
Traumatic brain injury (TBI) is a severe condition that leads to brain damage and affects brain function. Importantly, $T B I$ incurs public health costs due to its high mortality, and effective treatment for TBI is still lacking. Docosahexaenoic acid (DHA) has a neuroprotective effect that can reduce oxidative, apoptosis, and inflammatory processes. Administration of DHA after TBI attenuates oxidative stress and protein accumulation and is regarded as a potential therapeutic. Iduna is a regulator of parthanatos, and upregulation of Iduna reduces cellular damage and mitochondrial dysfunction. Thus, we speculated that overexpression of Iduna might promote DHA therapy in the treatment of $T B I$. Here, we found that after combination overexpression of Iduna and DHA in a mouse model of TBI, the expression of inflammatory factors was reduced, while the secretion of neuroprotective factors was increased. In addition, we found that these effects might be mediated by the Wnt/MDM2 pathway, and Iduna might be a therapeutic target for TBI.
\end{abstract}

Key words: DHA, TBI, Iduna, inflammation, Wnt/MDM2.

\section{Introduction}

Traumatic brain injury (TBI) is one of the most commonly observed injuries and is closely related to neurodegenerative disorders, including Parkinson's and Alzheimer's diseases, and causes many disabilities and deaths worldwide [6]. TBI severity can be divided into 3 stages according to the score evaluated by the Glasgow Coma Scale (GCS). Most TBIs are mild and present with only a self-limiting headache, dizziness, or confusion [10]. Docosahexaenoic acid $(\mathrm{DHA})$ is an essential unsaturated fatty acid that is critical for maintenance of the normal structure and physiological function of cells [32]. A previous study demonstrated that DHA alleviates cerebral ischaemia reperfusion injury while maintaining integrity of the blood-brain barrier and reducing its permeability [3]. Another study found that DHA exerts a protective role in cerebral microvascular endothelial cells in rats under oxygen or glucose deficiency stimulation [7]. DHA has been demonstrated to be a strong therapeutic agent for the treatment of the central nervous system with few side effects [16]. A previous study observed that treatment with DHA in a TBI mouse model reduced 
TBI injury through inhibiting the expression of apoptosis-related proteins [43]. Iduna is a newly discovered ubiquitin $\mathrm{E} 3$ ligase and has been regarded as an inhibitor of parthanatos [1]. In addition, a recent study reported that Iduna also protects cells from the damage induced by glutamate excitotoxicity or oxidative stress via inhibition of parthanatos [41]. However, the effect of Iduna in TBI models is not fully understood. A recent study suggested that there might be interactions between Iduna and the p53-MDM2 signalling pathway, which plays an important role in regulating pathological progression in TBI [38]. Here, we found that using DHA in a mouse model of TBI reduced the apoptosis of neuronal cells, and that DHA promoted the expression of neuroprotective factors at the gene and protein levels. We further observed that these effects might be mediated by the MDM2/ p53 signalling pathway. All these effects led to the recovery of brain function in $\mathrm{TBI}$ mice. Therefore, we speculate that DHA treatment represents a promising therapeutic method for TBI.

\section{Material and methods Antibody}

Antibody mouse ELISA kits (ab209882, ab65328, $a b 212160$, and ab139473) were purchased from Abcam. Anti-Iduna (ab201212), Wnt (ab15251), GSK-3 $\beta$ (ab32391), $\beta$-catenin (ab32572), MDM2 (ab16895), p-p53 (ab33889), p-53 (ab26), cleaved PARP-1 (ab32064), PARP-1 (ab32138), eNOS (ab76198), FGF21 (ab171941), VEGFR (ab32152), and HIF-1 $\alpha$ (ab1) antibodies were purchased from Abcam.

\section{Mouse model}

Ten C57/BL mice, 5 Iduna overexpression mice, and 5 Iduna knockout mice were purchased from Guangdong Medical Animal Experiment Centre. Mice were housed at $22-24^{\circ} \mathrm{C}$ with $40-60 \%$ humidity under a $12 \mathrm{~h} / 12 \mathrm{~h}$ light and dark cycle with freely available water and food. Then, mice were divided into 4 groups: TBI model (TM), TBI model with single DHA treatment (DT), TBI model with DHA combined with Iduna overexpression (DO), and TBI model with DHA combined with Iduna inhibition (DI).

\section{Ethics statement}

All animal experiments were performed under the guidelines of Directive 2010/63/EU of the Euro- pean Parliament on the protection of animals and were approved by the Committee of Baoji High-tech Hospital.

\section{TBI model construction}

Animals were secured on a stereotaxic frame, and a 20-mm midline incision was made over the skull. A unilateral craniectomy was performed using a hand drill with a $5 \mathrm{~mm}$ diameter trephine. The bone flap was removed, and the animals were administered an impact using a 4-mm impactor tip depth of $0.65 \mathrm{~mm}$ at a rate of $4 \mathrm{~m} / \mathrm{s}$ for $200 \mathrm{~ms}$. After the surgery, the bone flap was closed [14]. In the DHA treatment group, mice were treated with $50 \mathrm{mg} / \mathrm{kg} / \mathrm{day}$ DHA for 8 continuous days [8].

\section{Evaluation of brain function}

Morris water maze (MWM) experiments were performed to determine the neurological function of mice after TBI. The experiment was performed in a tank with a $124 \mathrm{~cm}$ diameter and $32 \mathrm{~cm}$ depth of water, and the temperature remained at approximately $22^{\circ} \mathrm{C}$. Mice were trained for 5 continuous days, and if the mice were able to swim to the hidden platform within $60 \mathrm{~s}$, they were allowed to stay on the platform for $15 \mathrm{~s}$. If the mice were unable to locate the platform within $60 \mathrm{~s}$, they were manually placed on the platform. The experiment was performed on day 7 , and traces of exploration, time spent in the target quadrant, and the number of platform crosses were analysed after the experiment.

\section{Cell culture and grouping}

HT-22 cells (SCC129) were purchased from Merck. Cells were cultured under a $37^{\circ} \mathrm{C}$ atmosphere with $5 \% \mathrm{CO}_{2}$ in $\mathrm{H}$-DMEM supplemented with $10 \%$ fetal bovine serum (FBS). Cells were divided into 4 groups: $\mathrm{NC}$ (TBI model), DA (TBI model with single DHA treatment), AO (TBI model with DHA combined with Iduna overexpression), and $\mathrm{Al}$ group (TBI model with DHA combined with Iduna inhibition). In the DHA treatment group, cells were treated with $20 \mu \mathrm{M} \mathrm{DHA}$ for $48 \mathrm{~h}$.

\section{Vector and cell model construction}

Full-length Iduna cDNA was obtained using the following primers: forward: 5'-GGACGTCGCAGGAAGCTTAAG-3', reverse: 5'-CAATGGAGGTGTCTGGT- 
GCT-3'. cDNA of Iduna and the pcDNA3.1 vector were digested with Xbal and EcoRI. After successful construction, the Iduna-pcDNA3.1 vector was transfected into HT-22 cells using Lipofectamine 3000 transfection reagent, and stably expressing cells were selected using $800 \mu \mathrm{g} / \mathrm{ml}$ G418. The Iduna knockdown vector was constructed using the CRISPR/ Cas9 system with the following primers: forward: 5'-CACCGGATAGCAGAAAACGTGCTTAC-3', reverse: 5'-CGTAAGCACGTTTTCTGCTATCCAAA-3'. Then, he vector was transfected into 293T cells to obtain the lentiviral vector, and HT-22 cells were infected. Stable Iduna knockdown cells were selected using $2 \mu \mathrm{g} / \mathrm{ml}$ puromycin. Cells were first seeded into 6-well plates, and a scratch was made in the monolayer using a plastic needle with a $9 \times 9$ square grid for $24 \mathrm{~h}$ to construct the TBI model in HT-22 cells.

\section{Total RNA extraction}

Brain tissues were isolated after treatment as described above. Total RNA extraction was performed according to the protocol. Then, tissues and cells were incubated with chloroform for $15 \mathrm{~s}$ with vigorous shaking. After centrifugation at $12,000 \mathrm{rpm}$ for $10 \mathrm{~min}$, the water phase was collected into a new tube. Samples were then mixed with ethanol and added onto the absorption column. After washing with washing buffer, samples were eluted from the column using elution buffer. The concentrations of RNA were determined using a Nanodrop 2000. RNA samples were stored at $-80^{\circ} \mathrm{C}$ until the subsequent experiments were performed.

\section{Reverse transcription and $\mathrm{qPCR}$}

Reverse transcription and $\mathrm{qPCR}$ were performed according to the protocol. Briefly, the reaction mixture was made up as recommended by the protocol. GPCR was performed with the following primers: IL-1 $\beta$ : forward: 5'-CAGGCAGGCAGTATCACTCA-3', reverse: 5'-AGCTCATATGGGTCCGACAT-3'; IL-6: forward: 5'-ACCAGAGGAAATTTCAAT-3', reverse: 5'-TGATGCACTTGCAGAAAACA-3'; IL-10: forward: 5'-GCCAGAGCCACATGCTCCTA-3', reverse: 5'-GATAAGGCTTGGCAACCCAAGTAA-3'; TNF- $\alpha$ : forward: 5'-CССТTGTCСТCACCCACAC-3', reverse: 5'-CTCCCTGGTAGATGGGTTCG-3'. The reaction was performed with the following steps: reverse transcription at $50^{\circ} \mathrm{C}$ for $15 \mathrm{~min}$ and denaturing at $95^{\circ} \mathrm{C}$ for $2 \mathrm{~min}$. The following steps were repeated for 45 cycles: denaturation at $95^{\circ} \mathrm{C}$ for $20 \mathrm{~s}$, annealing at 5 for $20 \mathrm{~s}$, and extension at $72^{\circ} \mathrm{C}$ for 2 min. Each experiment was independently repeated 3 times, and glyceraldehyde 3-phosphate dehydrogenase (GAPDH) was used as an internal control. The expression of each target gene was determined using the 2- $\Delta \Delta \mathrm{Cq}$ method [23].

\section{Western blotting analysis}

Brain tissues and cells were lysed in RIPA buffer supplemented with proteinase inhibitor cocktail. Supernatants were collected after centrifugation at $12,000 \mathrm{rpm}$ for $10 \mathrm{~min}$, and the protein concentration was determined using a BCA assay. Protein samples $(100 \mu \mathrm{g})$ were separated using SDS-PAGE electrophoresis and subsequently transferred onto PVDF membranes. Then, the membranes were blocked in 5\% skimmed milk followed by incubation with primary antibodies overnight at $4^{\circ} \mathrm{C}$ and secondary antibody for $1 \mathrm{~h}$ at room temperature. The expression of each target protein was detected using a chemiluminescent immunoassay and was analysed using Image-Pro Plus software.

\section{ELISA}

ELISA was performed according to the protocol. Briefly, serum from mice and culture medium were added to each well of a 96-well plate and incubated at $37^{\circ} \mathrm{C}$ for $90 \mathrm{~min}$, followed by incubation with target antibodies at $37^{\circ} \mathrm{C}$ for $60 \mathrm{~min}$. After washing with washing buffer, samples were incubated with $A B C$ working solution at $37^{\circ} \mathrm{C}$ for $30 \mathrm{~min}$. Samples were incubated with $\mathrm{TMB}$ agent for $25 \mathrm{~min}$ at $37^{\circ} \mathrm{C}$ followed by incubation with stop solution. The absorbance value at $450 \mathrm{~nm}$ was measured using a microplate reader (Multiskan FC, Thermo).

\section{Statistical analysis}

Data from each experiment are presented as the mean \pm S.E.M. Each experiment was independently repeated 3 times. One-way ANOVA was used to analyse differences between groups using SPSS 22.0 software. A $p$-value $<0.05$ was considered statistically significant.

\section{Results \\ Detection of brain function in mice}

The average escape latency of mice was $85.1 \pm 9.2$, $70.6 \pm 8.3,62.1 \pm 7.1,54.5 \pm 5.7$ and $46.9 \pm 5.1$ in the TM group; $78.6 \pm 7.8,65.2 \pm 6.1,57.6 \pm 4.9,48.3 \pm 4.1$ 
and $42.5 \pm 3.5$ in the DT group; $78.3 \pm 7.6,65.3 \pm 6.3$, $49.4 \pm 5.1,41.2 \pm 4.4$ and $32.4 \pm 3.4$ in the DO group; and $82.4 \pm 8.0,68.2 \pm 7.2,56.3 \pm 6.1,51.4 \pm 4.8$ and $44.1 \pm 4.1$ in the DI group. The average number of platform crossings in these groups was $1.7 \pm 0.3,2.6 \pm 0.6$, $4.5 \pm 0.8$ and $2.2 \pm 0.5$, respectively. The time spent in the correct quadrant in these groups was $16.2 \pm 2.5$, $19.3 \pm 3.4,29.4 \pm 4.5$ and $17.0 \pm 2.9$ s, respectively. The average escape latency was significantly decreased in the DO group on days 4 and 5 after treatment, while the average crossed platform number and the time spent in the correct quadrant were significantly increased in the DO group compared to the TM group. The viability rates of cells in the NC, DA, AO, and $\mathrm{Al}$ groups were $100.0 \pm 8.5,126.2 \pm 9.6,155.6 \pm 11.4$, and $96.3 \pm 8.2$, respectively. Expression of PARP1 in the NC, $\mathrm{AO}$, and $\mathrm{Al}$ groups was $0.73 \pm 0.04,1.00 \pm 0.06$, and $0.50 \pm 0.03$, respectively. These results indicated that overexpression of Iduna compared to DHA significantly recovered the brain function of mice and the viability of cells after TBI.

\section{Expression of inflammation-related factors in brain tissues}

The expression of interleukin (IL)- $1 \beta$ in the TM, DT, DO, and DI groups of the mouse model was 1.00 $\pm 0.16,0.82 \pm 0.08,0.43 \pm 0.06$, and $1.14 \pm 0.17$, respectively. The relative expression of IL- 6 in these groups was $1.00 \pm 0.13,0.76 \pm 0.15,0.47 \pm 0.08$, and 0.87 \pm 0.08 , respectively. The relative expression of IL-10 in these groups was $1.00 \pm 0.14,1.16 \pm 0.28,1.73 \pm 0.51$, and $1.24 \pm 0.23$, respectively. The relative expression of tumour necrosis factor $\alpha$ (TNF- $\alpha$ ) in these groups was $1.00 \pm 0.17,0.93 \pm 0.22,0.44 \pm 0.11$, and 0.92 \pm 0.14 , respectively (Fig. 2). The expression of IL-1 $\beta$ in the NC, DA, AO, and Al groups of the cell model was $1.00 \pm 0.10,0.71 \pm 0.06,0.34 \pm 0.03$, and $1.08 \pm 0.07$, respectively. The relative expression of IL- 6 in these groups was $1.00 \pm 0.15,0.76 \pm 0.14,0.43 \pm 0.11$, and $0.94 \pm 0.21$, respectively. The relative expression of $\mathrm{IL}-10$ in these groups was $1.00 \pm 0.14,1.23 \pm 0.21$, $1.86 \pm 0.31$, and $1.18 \pm 0.24$, respectively. The relative expression of TNF- $\alpha$ in these groups was $1.00 \pm 0.16$,
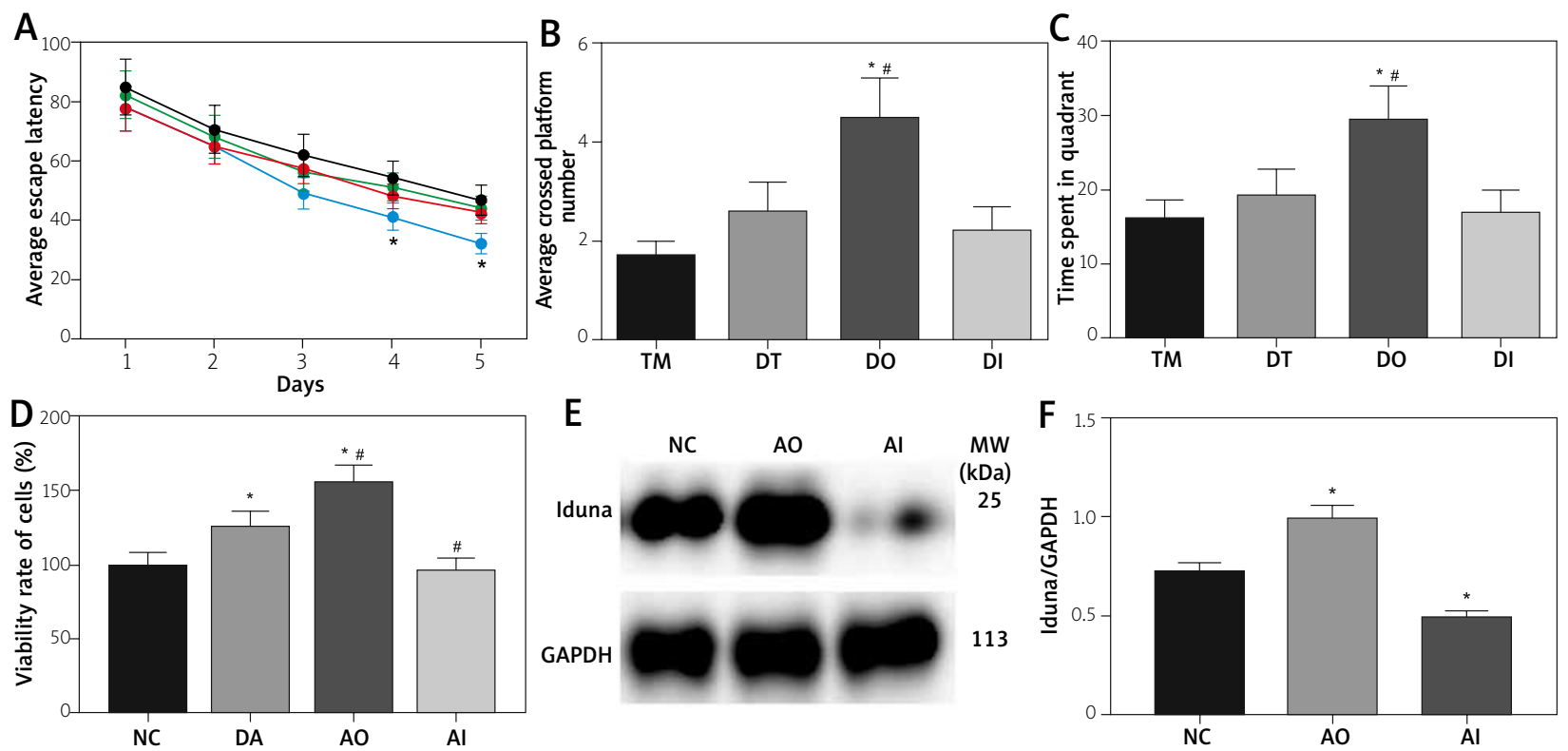

Fig. 1. Detection of brain function of mice and the effect of DHA on cellular viability. A) Average escape latency in each group. B) Average crossed platform number in each group. C) Time spent in target quadrant. D) Detection of cell viability. E) Expression of Iduna in cell of each group. F) Quantitative analysis of Iduna in cell. TM - TBI model group, DT - TBI model with single DHA treatment group, DO - TBI model with DHA combined with Iduna overexpression group, DI - TBI model with DHA combined with Iduna inhibition group. NC - TBI model group of cell, DA - TBI model with single DHA treatment group of cell, AO - TBI model with DHA combined with Iduna overexpression group of cell, AI - TBI model with DHA combined with Iduna inhibition group of cell. Each experiment was repeated 3 times independently. ${ }^{*} p<0.05$ compared with TM group, ${ }^{\#} p<0.05$ compared with DT group. 
A

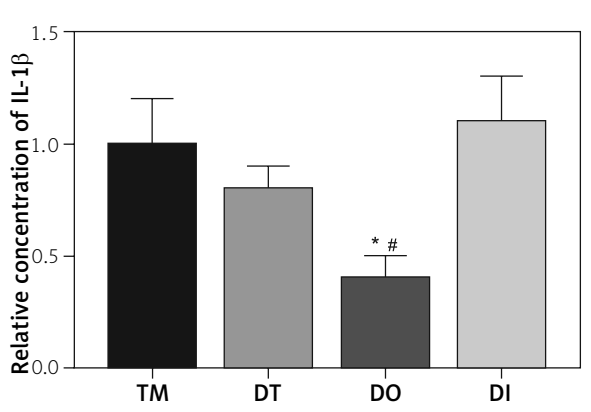

C

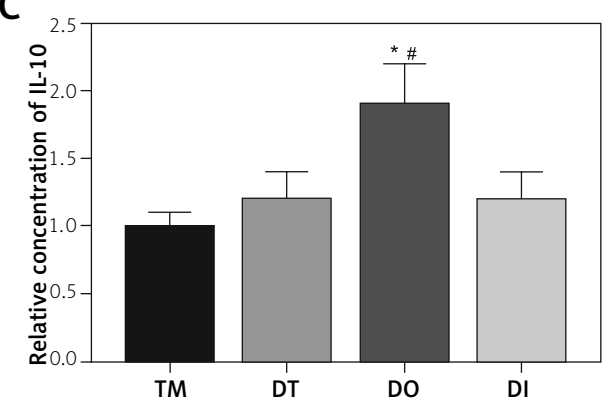

B

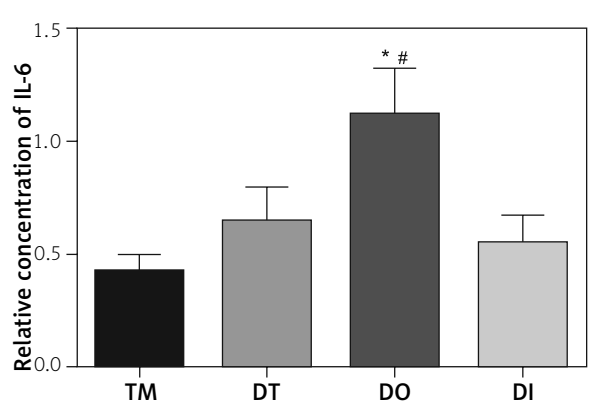

D

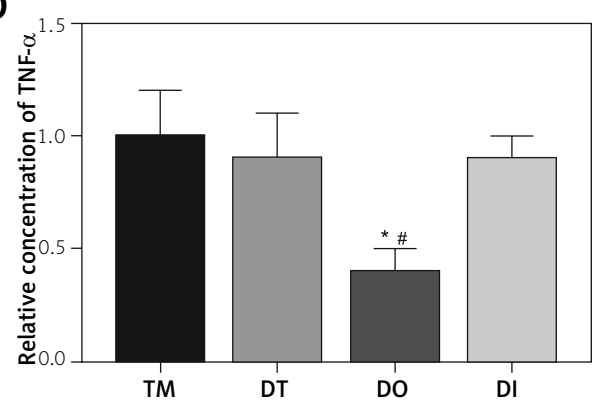

Fig. 2. Detection of inflammatory-related genes in brain tissue. A) Expression of IL-1 $\beta$. B) Expression of IL-6. C) Expression of IL-10. D) Expression of TNF- $\alpha$. TM - TBI model group, DT - TBI model with single DHA treatment group, DO - TBI model with DHA combined with Iduna overexpression group, DI - TBI model with DHA combined with Iduna inhibition group. Each experiment was repeated 3 times independently. ${ }^{*} p<0.05$ compared with TM group, ${ }^{\#} p<0.05$ compared with DT group.

$0.92 \pm 0.21,0.36 \pm 0.12$, and $0.85 \pm 0.17$, respectively (Fig. 3). The expression of IL-1 $\beta$, IL-6, and TNF- $\alpha$ was significantly reduced in the DO group, while the expression of IL-10 was significantly increased in the DO group. These results showed that the inflammatory process was significantly inhibited after treatment with DHA combined with Iduna.

\section{Detection of target proteins in brain tissues}

The ratio of cleaved poly(ADP-ribose) polymerase-1 (PARP-1)/PARP-1 in the TM, DT, DO, and DI groups of the mouse model was $1.27 \pm 0.13,1.25 \pm 0.13,0.98$ \pm 0.10 , and $1.85 \pm 0.19$, respectively. The expression of endothelial nitric oxide synthase (eNOS) in these groups was $0.29 \pm 0.03,0.68 \pm 0.07,0.93 \pm 0.09$, and $0.29 \pm 0.03$, respectively. The expression of FGF21 in these groups was $0.18 \pm 0.02,0.56 \pm 0.06,0.77 \pm 0.08$, and $0.36 \pm 0.04$, respectively. The expression of vascular endothelial growth factor receptor (VEGFR) in these groups was $0.52 \pm 0.05,0.92 \pm 0.09,1.34 \pm 0.13$, and $0.68 \pm 0.07$, respectively. The expression of HIF- $1 \alpha$ in these groups was $1.02 \pm 0.10,1.07 \pm 0.11,0.76$ \pm 0.08 , and $1.25 \pm 0.12$, respectively (Fig. 3 ). The ratio of cleaved PARP-1/PARP-1 in cultured cells in the NC, $\mathrm{DA}, \mathrm{AO}$, and $\mathrm{Al}$ groups was $0.31 \pm 0.03,0.32 \pm 0.03$, $0.11 \pm 0.01$, and $0.24 \pm 0.15$, respectively. The expression of eNOS in these groups was $0.12 \pm 0.03,0.37$ $\pm 0.03,0.53 \pm 0.05$, and $0.04 \pm 0.005$, respectively. The expression of FGF2 1 in these groups was $0.47 \pm 0.03$, $1.08 \pm 0.07,1.28 \pm 0.08$, and $0.78 \pm 0.04$, respectively. The expression of VEGFR in these groups was 0.53 $\pm 0.03,1.04 \pm 0.06,1.22 \pm 0.08$, and $0.82 \pm 0.06$. The expression of HIF- $1 \alpha$ in these groups was $1.18 \pm 0.11$, $1.15 \pm 0.10,0.53 \pm 0.04$ and $0.85 \pm 0.06$, respectively (Fig. 4). The expression of protective factors, including eNOS, FGF21, and VEGFR, was significantly increased in the DO group, while the ratio of cleaved PARP-1/ PARP-1 and the expression of HIF- $1 \alpha$ were significantly decreased in the DO group.

\section{Detection of the Wnt/GSK-3 $\beta$ signalling pathway}

The expression of Wnt in the TM, DT, DO, and DI groups in the mouse model was $1.55 \pm 0.16,1.51$ $\pm 0.15,1.96 \pm 0.20$, and $0.75 \pm 0.08$, respectively. The expression of glycogen synthase kinase- $3 \beta$ (GSK-3 $\beta$ ) in these groups was $1.72 \pm 0.17,1.19 \pm 0.12,0.92$ 

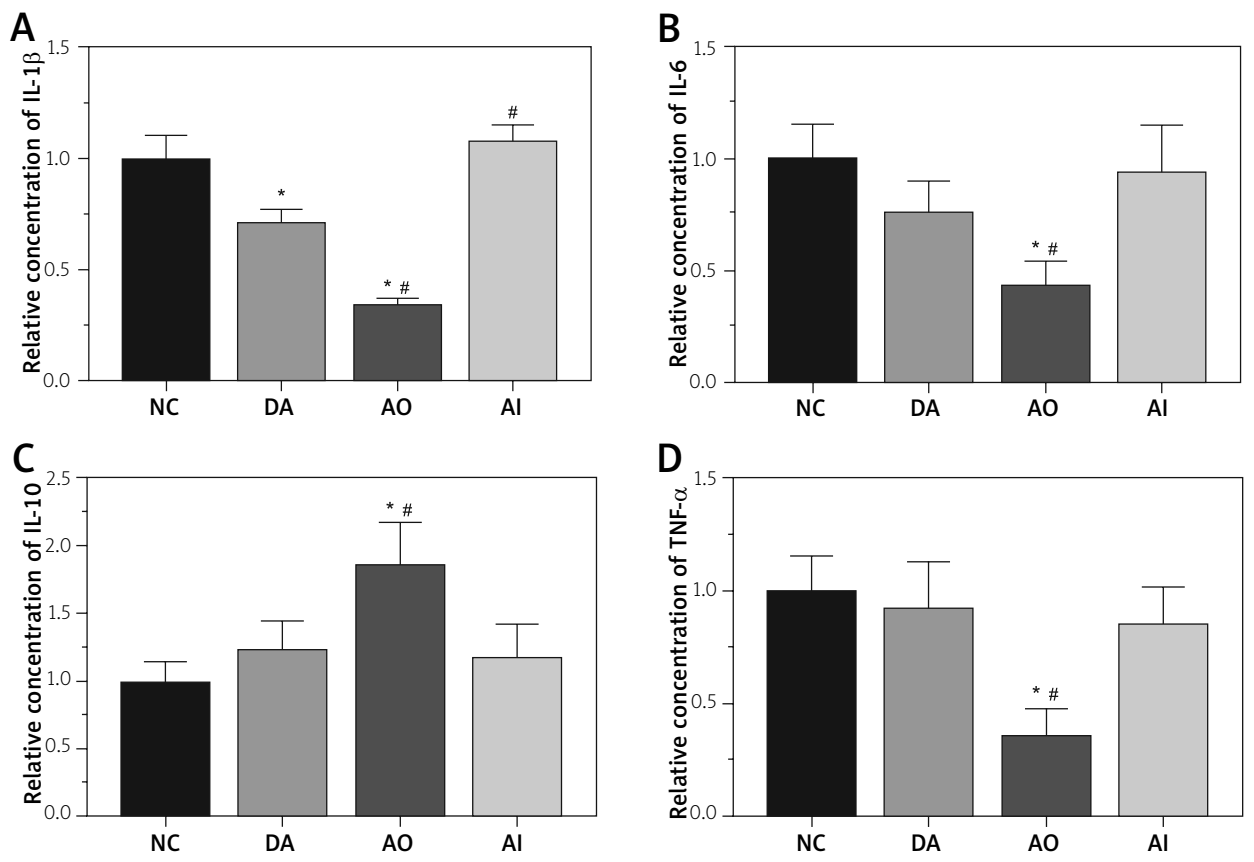

Fig. 3. Detection of inflammatory related genes in cell. A) Expression of IL-1ß. B) Expression of IL-6. C) Expression of IL-10. D) Expression of TNF- $\alpha$. NC - TBI model group of cell, DA - TBI model with single DHA treatment group of cell, AO - TBI model with DHA combined with Iduna overexpression group of cell, Al - TBI model with DHA combined with Iduna inhibition group of cell. Each experiment was repeated 3 times independently. ${ }^{*} p<0.05$ compared with TM group, ${ }^{*} p<0.05$ compared with DT group.

\pm 0.09 , and $1.68 \pm 0.17$, respectively. The expression of $\beta$-catenin in these groups was $1.53 \pm 0.15$, $2.00 \pm 0.20,2.73 \pm 0.27$, and $2.35 \pm 0.24$, respectively. The expression of MDM2 in these groups was $0.86 \pm 0.09,1.26 \pm 0.13,1.77 \pm 0.18$, and $0.44 \pm 0.04$, respectively. The ratio of p-p53/p53 in these groups was $1.48 \pm 0.15,1.16 \pm 0.12,0.83 \pm 0.08$, and 1.52 \pm 0.15 , respectively (Fig. 5). The expression of Wnt in the NC, DA, AO, and Al groups in the cell model was $0.41 \pm 0.02,0.71 \pm 0.04,0.87 \pm 0.05$, and $0.42 \pm 0.02$, respectively. The expression of GSK-3 $\beta$ in these groups was $1.21 \pm 0.15,1.08 \pm 0.13,0.81 \pm 0.08$, and $1.14 \pm 0.13$, respectively. The expression of $\beta$-catenin in these groups was $0.15 \pm 0.01,0.56 \pm 0.03,0.87$ \pm 0.05 , and $0.41 \pm 0.03$, respectively. The expression of MDM2 in these groups was $0.26 \pm 0.02,0.61$ $\pm 0.04,0.74 \pm 0.06$, and $0.14 \pm 0.01$, respectively. The ratio of $p-p 53 / p 53$ in these groups was $0.22 \pm 0.02$, $0.16 \pm 0.02,0.12 \pm 0.01$, and $0.20 \pm 0.02$, respectively (Fig. 6). The expression of GSK-3 $\beta$ and $\beta$-catenin was significantly decreased in the DO group, while MDM2 was significantly increased in the DO group, consistent with the increase in Wnt expression, indicating that Wnt/MDM2 might mediate the protective effect of DHA combined with Iduna treatment.

\section{Detection of protective factor concentrations in culture medium}

The concentrations of VEGF in serum samples of mice in the TM, DT, DO, and DI groups were 95.6 $\pm 7.3,115.3 \pm 8.1,154.7 \pm 9.2$, and $101.6 \pm 7.4 \mathrm{pg} / \mathrm{ml}$, respectively. The concentrations of $\mathrm{NO}$ in the serum samples of mice in each group were $1.6 \pm 0.1,2.5$ $\pm 0.3,5.1 \pm 0.6 \mathrm{~m}$ and $2.1 \pm 0.3 \mathrm{nM}$, respectively. The concentrations of FGF21 in each group were 105.2 $\pm 5.3,175.3 \pm 7.6,265.7 \pm 9.8$, and $152.1 \pm 6.7 \mathrm{pg} / \mathrm{ml}$, respectively. The relative concentrations of ROS in each group were $1.0 \pm 0.1,0.8 \pm 0.1,0.3 \pm 0.1$, and 0.9 \pm 0.1 , respectively (Fig. 7). The concentrations of VEGF in the culture medium of cells in the NC, DA, AO, and Al groups were $81.2 \pm 6.8,103.5 \pm 7.8,143.6 \pm 8.9$, and $92.4 \pm 7.2 \mathrm{pg} / \mathrm{ml}$, respectively. The concentrations of $\mathrm{NO}$ in the serum samples of mice in each group were $1.2 \pm 0.1,2.4 \pm 0.4,4.5 \pm 0.5$, and $1.6 \pm 0.2 \mathrm{nM}$, 

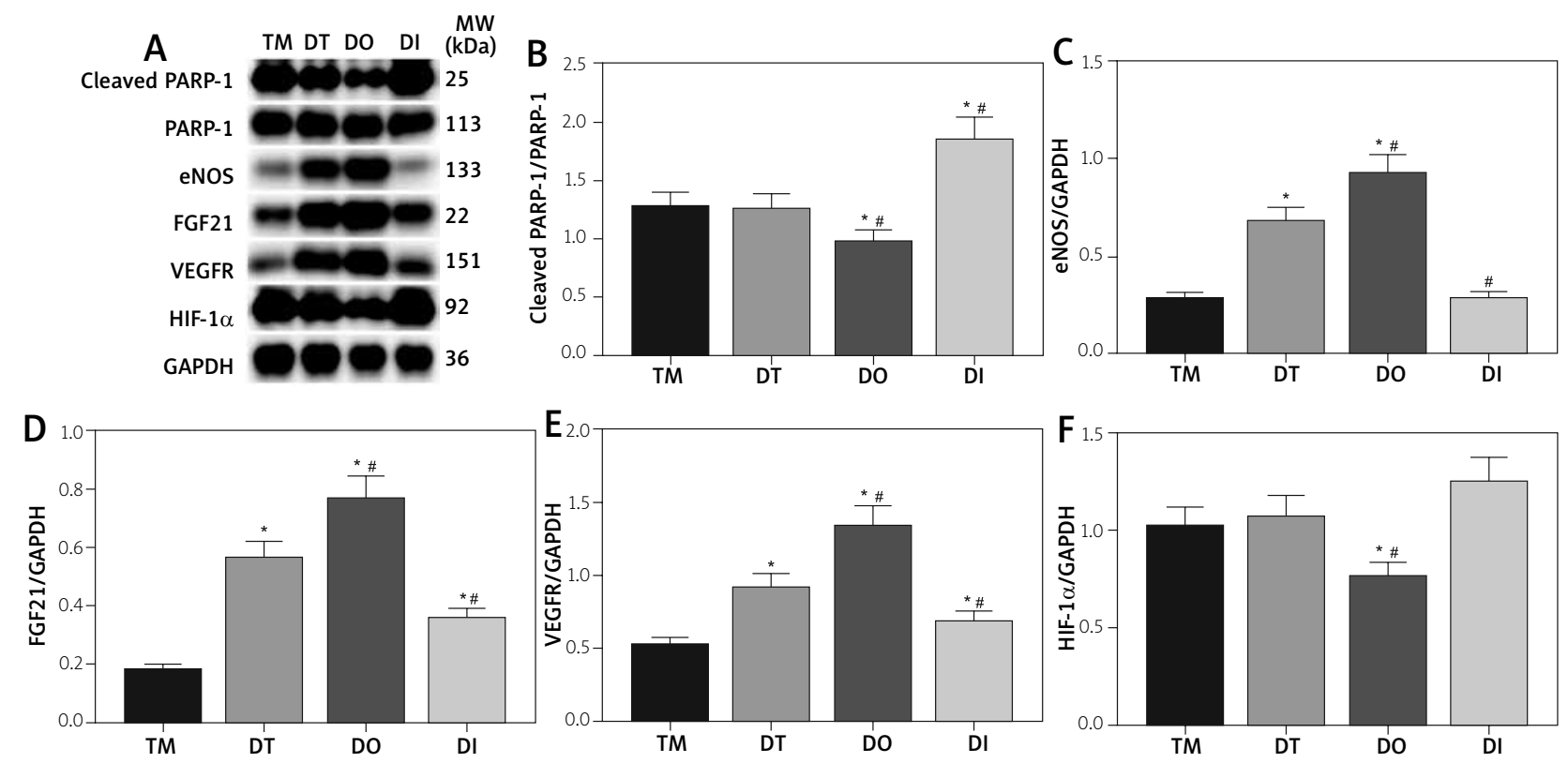

Fig. 4. Expression of protective factors in brain tissue. A) Expression of p-PARP-1, PARP-1, eNOS, FGF21, VEGFR, and HIF-1 $\alpha$. B-F) Quantitative analysis of target protein. TM - TBI model group, DT - TBI model with single DHA treatment group, DO - TBI model with DHA combined with Iduna overexpression group, DI - TBI model with DHA combined with Iduna inhibition group. Each experiment was repeated 3 times independently. ${ }^{*} p<0.05$ compared with TM group, ${ }^{*} p<0.05$ compared with DT group.
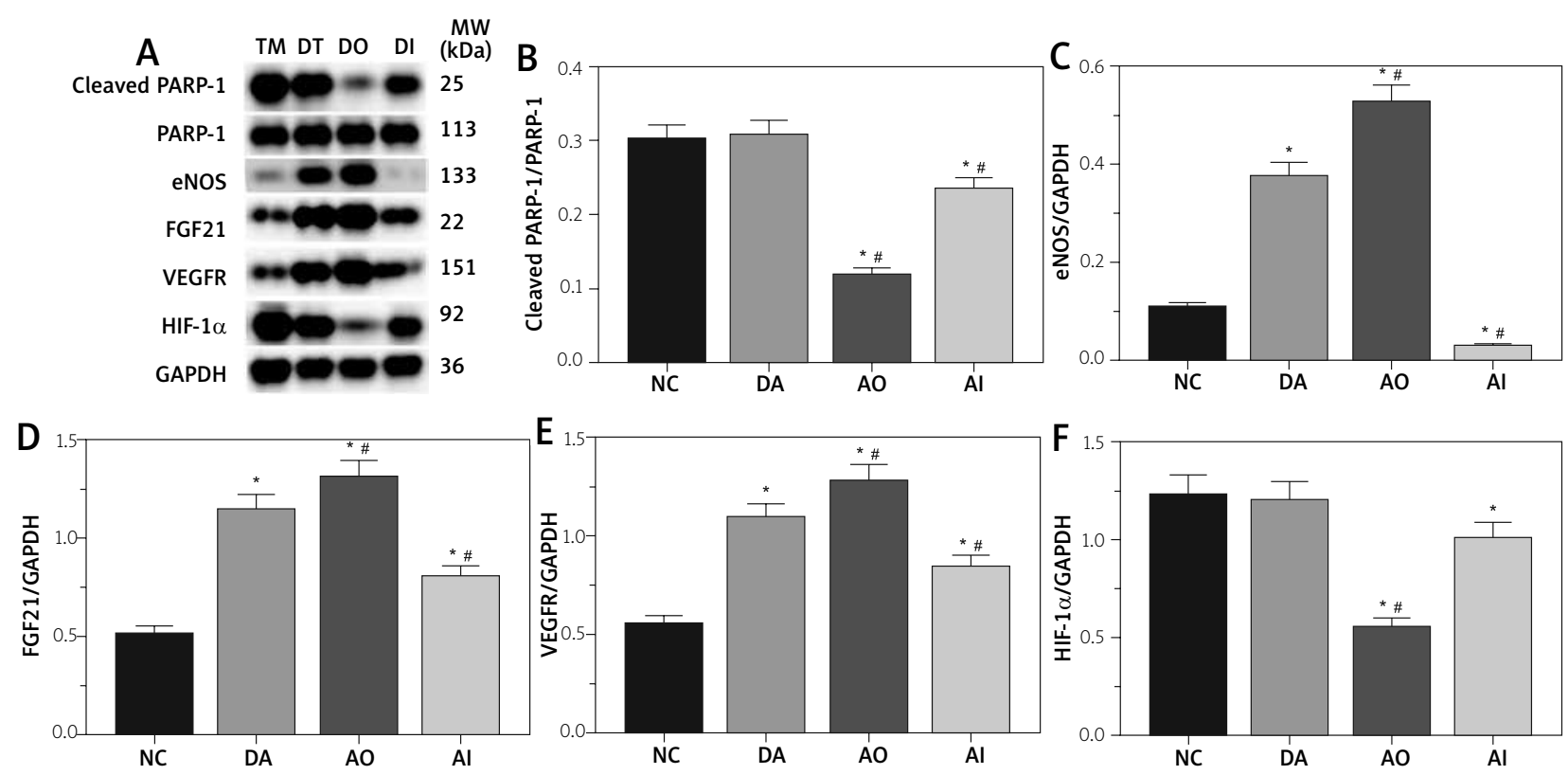

Fig. 5. Expression of protective factors in cell. A) Expression of p-PARP-1, PARP-1, eNOS, FGF21, VEGFR and HIF-1 $\alpha$. B-F) Quantitative analysis of target protein. NC - TBI model group of cell, DA - TBI model with single DHA treatment group of cell, AO - TBI model with DHA combined with Iduna overexpression group of cell, Al - TBI model with DHA combined with Iduna inhibition group of cell. Each experiment was repeated 3 times independently. ${ }^{*} p<0.05$ compared with TM group, ${ }^{*} p<0.05$ compared with DT group. 

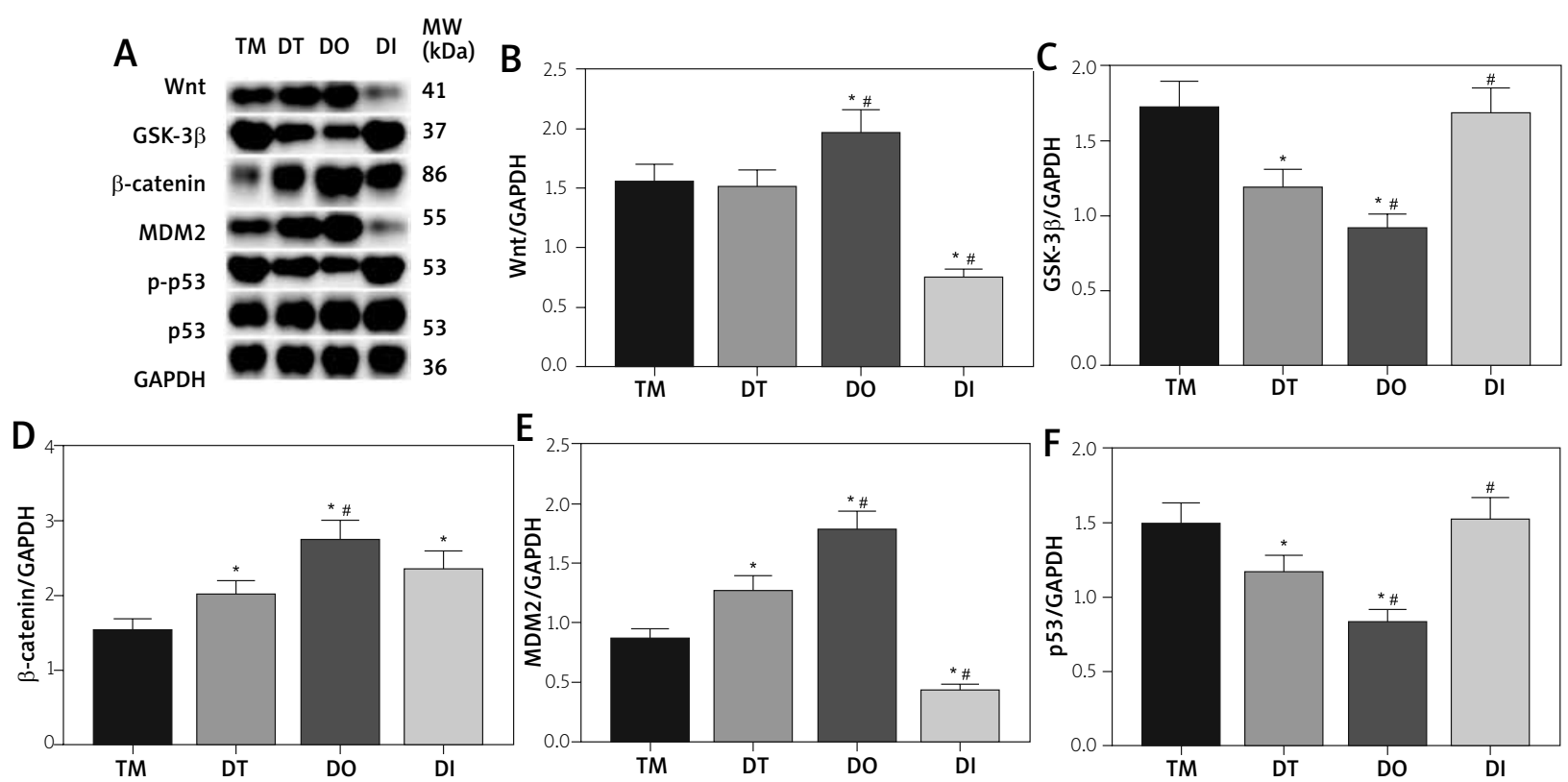

Fig. 6. Expression of protective factors in brain tissue. A) Expression of Wnt, GSK-3 $\beta$, $\beta$-catenin, MDM2, p-p53, and p53. B-F) Quantitative analysis of target protein. TM - TBI model group, DT - TBI model with single DHA treatment group, DO - TBI model with DHA combined with Iduna overexpression group, DI TBI model with DHA combined with Iduna inhibition group. Each experiment was repeated 3 times independently. ${ }^{*} p<0.05$ compared with TM group, ${ }^{*} p<0.05$ compared with DT group.
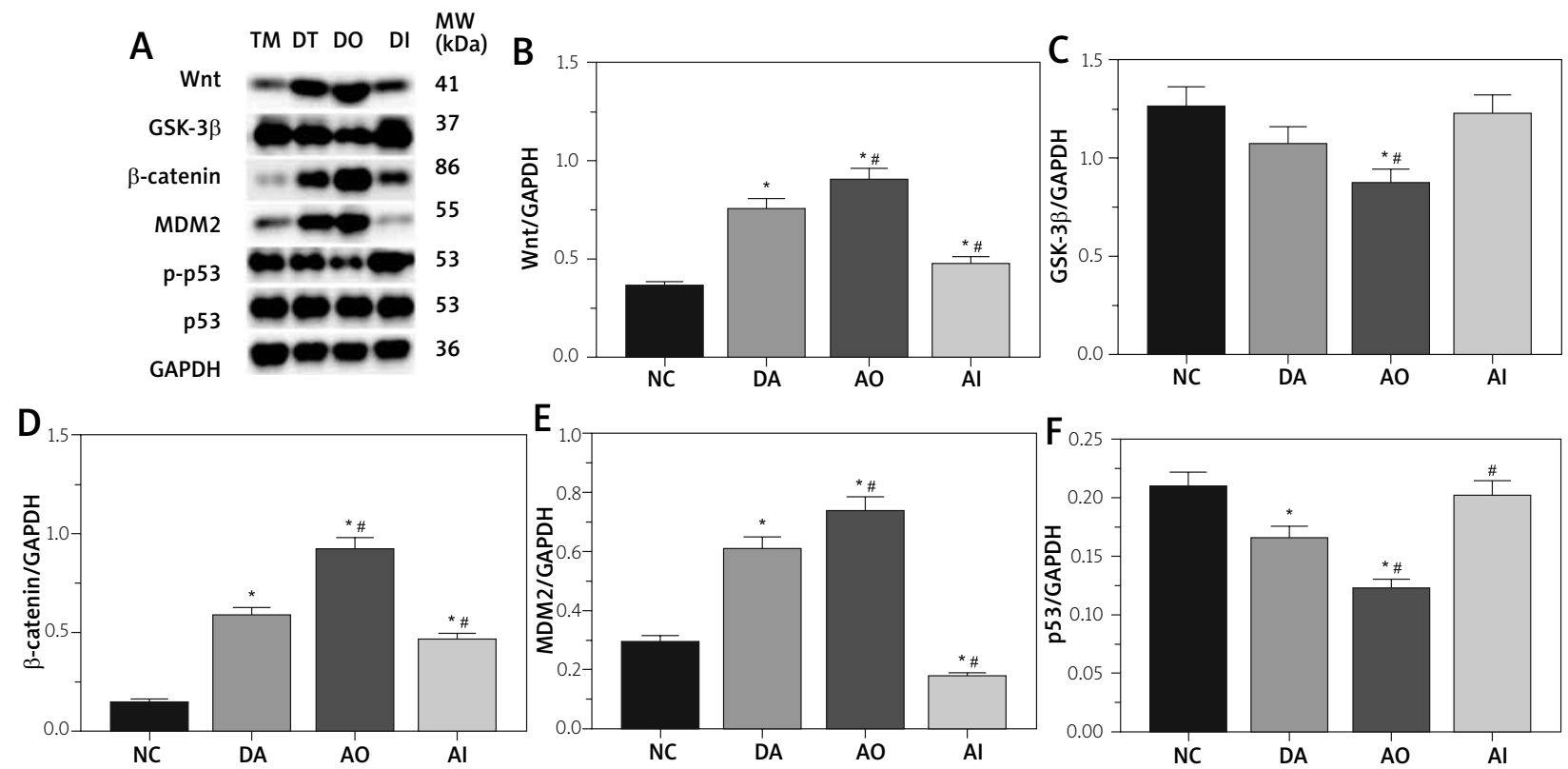

Fig. 7. Expression of protective factors in cell. A) Expression of Wnt, GSK-3 $\beta$, $\beta$-catenin, MDM2, p-p53 and p53. B-F) Quantitative analysis of target protein. NC - TBI model group of cell, DA - TBI model with single DHA treatment group of cell, AO - TBI model with DHA combined with Iduna overexpression group of cell, Al - TBI model with DHA combined with Iduna inhibition group of cell. Each experiment was repeated 3 times independently. ${ }^{*} p<0.05$ compared with TM group, ${ }^{\#} p<0.05$ compared with DT group. 

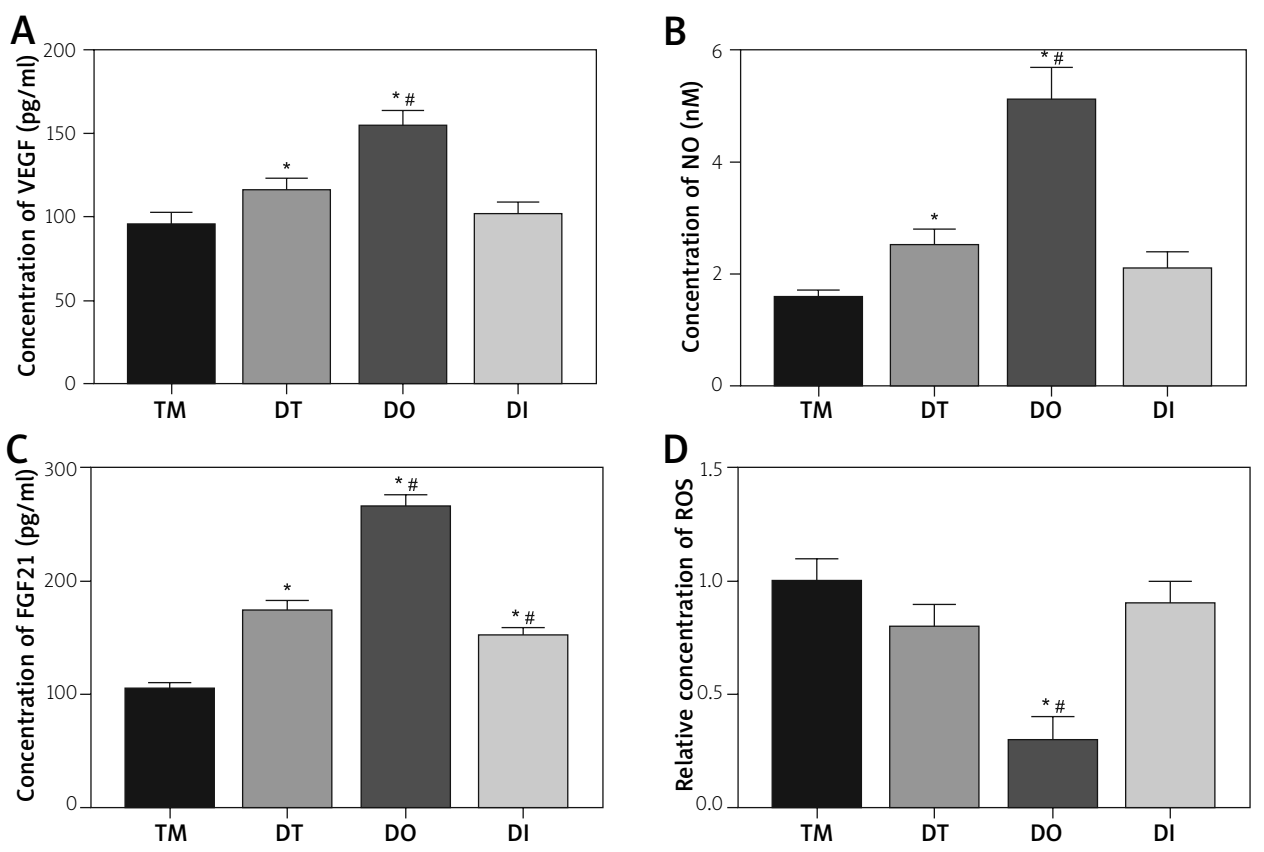

Fig. 8. Detection of inflammatory related cytokines in serum sample. A) Concentration of VEGF. B) Concentration of NO. C) Concentration of FGF21. D) Relative concentration of ROS. TM - TBI model group, DT - TBI model with single DHA treatment group, DO - TBI model with DHA combined with Iduna overexpression group, DI - TBI model with DHA combined with Iduna inhibition group. Each experiment was repeated 3 times independently. ${ }^{*} p<0.05$ compared with TM group, ${ }^{*} p<0.05$ compared with DT group.
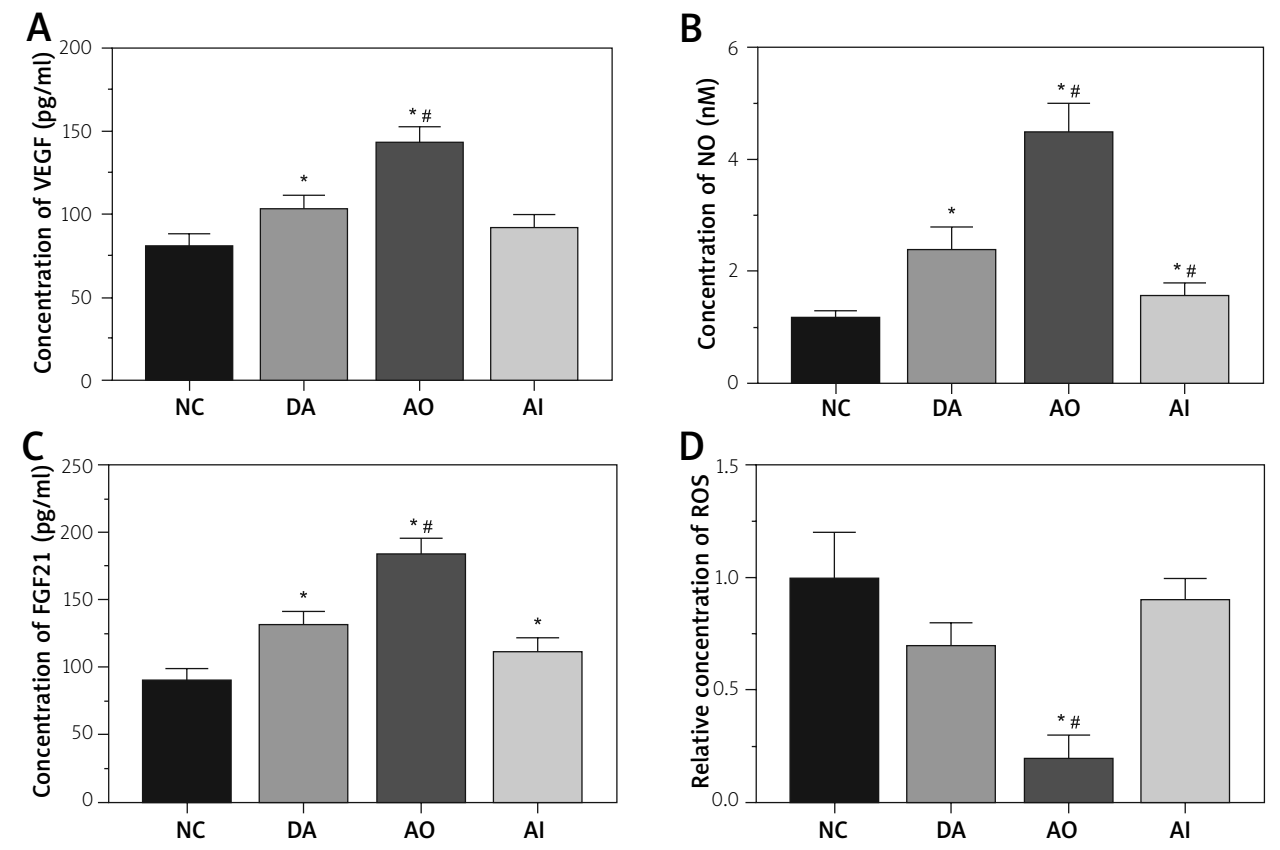

Fig. 9. Detection of inflammatory related cytokines in serum sample. A) Concentration of VEGF. B) Concentration of NO. C) Concentration of FGF21. D) Relative concentration of ROS. NC - TBI model group of cell, DA - TBI model with single DHA treatment group of cell, AO - TBI model with DHA combined with Iduna overexpression group of cell, Al - TBI model with DHA combined with Iduna inhibition group of cell. Each experiment was repeated 3 times independently. ${ }^{*} p<0.05$ compared with TM group, ${ }^{*} p<0.05$ compared with DT group. 
respectively. The concentrations of FGF21 in each group were $91.2 \pm 7.3,132.5 \pm 9.1,184.7 \pm 11.2$, and $113.2 \pm 8.4 \mathrm{pg} / \mathrm{ml}$, respectively. The relative concentrations of ROS in each group were $1.0 \pm 0.2,0.7 \pm 0.1$, $0.2 \pm 0.1$, and $0.9 \pm 0.1$, respectively (Fig. 8). The concentration of protective cytokines was increased in response to Iduna overexpression combined with DHA treatment, while the relative concentration of ROS was decreased. These results showed that Iduna overexpression combined with DHA treatment promotes the secretion of protective cytokines.

\section{Discussion}

Traumatic brain injury is primarily caused by damage from an external mechanical force to the brain, resulting in temporary or permanent damage to physical and psychosocial functions [19]. TBI is not only the primary cause of disability among young adults but also leads to healthcare costs due to the high incidence rate and long-term sequelae [29]. However, effective treatment for TBI is still limited. The metabolism of DHA leads to the production of docosanoids, also known as neuroprotectins, which inhibit the activation of proinflammatory cells and promote the antiapoptotic process [26].

A previous study found that Iduna inhibits cell death induced by PARP-1; thus, we speculated that overexpression of Iduna might contribute to the therapeutic effect of DHA in the treatment of TBI. Activation of the inflammatory response occurs after $\mathrm{TBI}$, and the primary characteristics of this process are the activation of inflammatory cells and the release of inflammatory cytokines [44]. Cellular damage induced by TBI leads to the release of DNA, RNA, and other compounds, which further bind to Toll-like receptors and induce the secretion of proinflammatory cytokines, including IL-1 $\beta$, IL-6, and TNF- $\alpha$ [4]. In addition to this mechanism, damage to brain tissues also induces activation of the classical inflammatory response, leading to the release of proinflammatory cytokines [11]. According to a previous study, the concentrations of IL- $1 \beta$, TNF- $\alpha$, and IL-6 peak at 3-9 hours after TBI [2]. IL-10 is regarded as an anti-inflammatory cytokine during the inflammatory response process, and increased expression of IL-10 in the brain promotes the survival of neurons [37]. IL-10 inhibits the synthesis of proinflammatory cytokines and limits the inflammatory process by reducing the expression of cytokine receptors and activating these receptors. Thus, IL-10 expression might alleviate damage in brain tissue after TBI. Here, we found that after overexpression of Iduna, the expression of inflammatory promoting factors was decreased compared to that in the DHA treatment group, while expression of IL-10 was increased. In addition, we observed that inhibition of Iduna expression reversed this effect. Therefore, overexpression of Iduna contributes to the therapeutic effect of DHA in a mouse model of TBI.

Poly(ADP-ribose) polymerase-1 (PARP-1) catalyses nicotinamide adenine dinucleotide (NAD+) to form and attach ADP-ribose polymers (PARs) to proteins [34]. Activation of PARP-1 is induced by DNA damage, and activated PARP-1 facilitates repair of the DNA base after DNA damage by recruiting DNA polymerases to the break site of DNA, maintaining the integrity and stability of DNA [30]. Activation of PARP-1 promotes neuronal cell death through failure of the energy supply, which is induced by the accumulation of NAD+, leading to passive cell death. A recent study found that activation of PARP-1 directly induces mitochondrial dysfunction, decreasing ATP production by inhibiting the activity of electron transport chain complex IV [17]. Here, we found that overexpression of Iduna combined with DHA leads to reduced expression of PARP-1, which might contribute to the therapeutic effect of DHA. We explored the detailed mechanism underlying this effect by examining other target proteins in the brain tissue. VEGFR is the receptor of VEGF, which promotes the downstream angiogenic effects of VEGF, such as the proliferation and survival of endothelial cells [12]. In addition, expression of VEGFR is critical for the angiogenesis process in brain tissues after TBI. A previous study demonstrated that after TBI, expression of VEGFR is increased [20]. Elevated expression of VEGFR activates the pro-proliferation signalling pathway [18]. The PI3K/AKT pathway might contribute to this effect through its ability to promote the angiogenesis process, and upregulation of VEGFR might promote the recovery of brain tissues after TBI. Here, the treatment of DHA combined with Iduna overexpression significantly increased the expression of VEGFR and promoted expression of its downstream molecule eNOS, which is also critical for angiogenesis [28]. Increased expression of eNOS leads to multiple effects, including angiogenesis and cell survival [15].

Nitric oxide (NO) is a key regulator of cerebral circulation, and NO production inhibits the adhesion 
of inflammatory cells to the surface of endothelial cells, further inhibiting the inflammatory response [27]. NO is produced by eNOS in brain tissue, and the production of cerebral NO is also reduced in cerebral blood flow after TBI [13]. A recent study showed that after applying the NOS substrate L-arginine, TBI outcomes were improved [24]. Another study also reported that NO expression was reduced during the first week after TBI, indicating that the expression of eNOS was also reduced [39]. Here, we noticed that eNOS expression was increased after the combination of Iduna overexpression and DHA treatment compared to the control group, so we speculated that Iduna overexpression might promote the therapeutic effect of DHA by promoting the expression of eNOS and VEGFR. FGF21 is a regulator of TBI according to primate models and has been regarded as a therapeutic target for TBI due to the great effect of FGF21 on the regulation of metabolic benefits; however, the effect of FGF21 in the central nervous system has not been fully explored. Another study showed that FGF21 promotes cell survival in an AKT-dependent manner while inhibiting the expression of GSK-3 $\beta$ [21], and administration of FGF21 reduces damage to brain tissues after TBI [9]. HIF- $1 \alpha$ is upregulated under hypoxic conditions and is rapidly degraded, and a recent study found that the inhibited expression of HIF-1 $\alpha$ during the acute phase of TBI was neuroprotective [36].

A previous study reported the expression of HIF- $1 \alpha$ in brain tissue after TBI [22]. Using HIF-1 $\alpha$ knockout mice, researchers found that the apoptosis process of hypoxia was reduced in response to TBI [5]. In addition, using an inhibitor of HIF- $1 \alpha$ reduced the damage to brain tissue after TBI [39]. These results showed that inhibition of HIF-1 $\alpha$ might contribute to the therapeutic effect of TBI. In addition, we also observed that the concentrations of NO, VEGF, and FGF21 in serum samples of mice were increased, while concentrations of ROS were reduced after treatment with DHA combined with Iduna overexpression, indicating that the combination of Iduna overexpression and DHA treatment improves brain function after TBI.

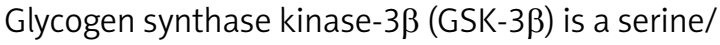
threonine kinase, and a previous study reported that GSK-3 $\beta$ strongly inhibits neuroprotection and survival in resting cells while promoting the apoptotic process by interacting with a wide range of molecules [40]. The primary downstream target of GSK-3 $\beta$ is $\beta$-catenin, which is under the control of the Wnt signalling pathway. However, the effect of the Wnt signalling pathway on $\beta$-catenin is not clear. Some studies have shown that activation of the Wnt pathway leads to inhibition of GSK-3 $\beta$ expression, which in turn reduces the degradation of $\beta$-catenin and increases its expression [25]. Other studies observed that activation of GSK-3 $\beta$ increases the activation of $\beta$-catenin, initiated by damage in brain tissues [42]. Another study found that inhibition of upstream mol-

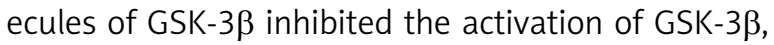
while increasing the expression of $\beta$-catenin reduced damage in a $\mathrm{CCl}$ model [31]. Here, we found that expression of Wnt was increased while expression of GSK-3 $\beta$ was decreased after Iduna overexpression combined with DHA treatment, and these might be possible mechanisms that protect the brain tissues from damage. A recent study indicated that the Wnt signalling pathway interacts with the MDM2/p53 pathway; thus, we speculated that the MDM2/p53 pathway also contributes to the therapeutic effect of combined DHA treatment and Iduna overexpression. Overexpression of $\beta$-catenin stabilizes $p 53$ while inhibiting the effect of protein degradation mediated by the MDM2-proteasomal system [33]; however, activation of p53 in turn reduces the expression of $\beta$-catenin in a GSK-3 $\beta$-dependent manner [35]. Thus, the interaction between the Wnt $/ \beta$-catenin and MDM2/p53 pathways is critical for cancer development, but the effect of these pathways in TBI is not fully understood. In the present study, we found that upregulated expression of MDM2 led to the downregulation of activated p53, which in turn promoted the expression of $\beta$-catenin, resulting in the promotion of cellular proliferation and angiogenesis processes that are critical for the recovery of brain tissues after TBI. Therefore, DHA treatment combined with Iduna overexpression might represent a therapeutic modality for TBI. However, the present study lacks experiments in human trials, which limits the application of DHA and Iduna combinations for the treatment of TBI. These experiments will be performed in our future study.

\section{Disclosure}

The authors report no conflict of interest.

\section{References}

1. Andrabi SA, Kang HC, Haince JF, Lee YI, Zhang J, Chi ZK, West AB, Koehler RC, Poirier GG, Dawson TM, Dawson VL. Dawson, Iduna 
protects the brain from glutamate excitotoxicity and stroke by interfering with poly(ADP-ribose) polymer-induced cell death. Nat Med 2011; 17: 692-699.

2. Bachstetter AD, Rowe RK, Kaneko M, Goulding D, Lifshitz J, Van Eldik LJ. The p38alpha MAPK regulates microglial responsiveness to diffuse traumatic brain injury. J Neurosci 2013; 33: 6143 6153.

3. Benjamin JH, Regina FF, Sora QK, Victoria DD, Shelley NJ, Lei L, Brenna JT, Brian PH, Christopher BG, Jessica ME. Acyl-CoA synthetase 6 enriches seminiferous tubules with the $\omega$ - 3 fatty acid docosahexaenoic acid and is required for male fertility in the mouse. J Biol Chem 2019; 294: 14394-14405.

4. Buchanan MM, Hutchinson M, Watkins LR, Yin H. Toll-like receptor 4 in CNS pathologies. J Neurochem 2010; 114: 13-27.

5. Carmeliet P, Dor Y, Herbert JM, Fukumura D, Brusselmans K, Dewerchin M, Neeman M, Bono F, Abramovitch R, Maxwell P, Koch CJ, Ratcliffe P, Moons L, Jain RK, Collen D, Keshert E. Role of HIF-1a in hypoxia-mediated apoptosis, cell proliferation and tumour angiogenesis. Nature 1998; 394: 485-490.

6. Carney N, Totten AM, O'Reilly C, Ullman JS, Hawryluk GW, Bell MJ, Bratton SL, Chesnut R, Harris OA, Kissoon N, Rubiano AM, Shutter L, Tasker RC, Vavilala MS, Wilberger J, Wright DW, Ghajar J. Guidelines for the management of severe traumatic brain injury. Neurosurgery 2017; 80: 6-15.

7. Chen X, Wang Q, Zhan L, Shu A. Effects and mechanisms of docosahexaenoic acid on the generation of angiopoietin-2 by rat brain microvascular endothelial cells under an oxygen- and glucose-deprivation environment. SpringerPlus 2016; 5: 1518.

8. Chen YC, Yan YH, Liu HZ, Qiu FF, Liang CL, Zhang QF, Huang RY, Han L, Lu CJ, Dai ZH. Dihydroartemisinin ameliorates psoriatic skin inflammation and its relapse by diminishing CD8 + T-cell memory in wild-type and humanized mice. Theranostics 2020; 10: 10466-10482.

9. Chen J, Hu J, Liu H, Xiong Y, Zou YC, Huang WT, Shao MJ, Wu JM, Yu L, Wang XJ, Wang X, Lin L. FGF21 protects the blood-brain barrier by upregulating PPARgamma via FGFR1/-klotho after traumatic brain injury. J Neurotrauma 2018; 35: 2091-2103.

10. Finkbeiner NW, Max JE, Longman S, Debert C. Knowing what we don't know: Long-Term psychiatric outcomes following adult concussion in sports. Can J Psychiatry 2016; 61: 270-276.

11. Hellewell S, Semple BD, Morganti-Kossmann MC. Therapies negating neuroinflammation after brain trauma. Brain Res 2016; 1640: 36-56.

12. Hicklin DJ, Ellis LM. Role of the vascular endothelial growth factor pathway in tumor growth and angiogenesis. J Clin Oncol 2005; 23: 1011-1027.

13. Hlatky R, Goodman JC, Valadka AB, Robertson CS. Role of nitric oxide in cerebral blood flow abnormalities after traumatic brain injury. J Cereb Blood Flow Metab 2003: 23: 582-588.

14. Joon HS, Miloni SD, Frances C, Jorge EC. Myeloid Pannexin-1 mediates acute leukocyte infiltration and leads to worse outcomes after brain trauma. J Neuroinflammation 2020; 17: 245.

15. Kashiwagi S, Izumi Y, Gohongi T, Demou ZN, Xu L, Huang PL, Buerk DG, Munn LL, Jain RK, Fukumura D. NO mediates mural cell recruitment and vessel morphogenesis in murine melanomas and tissue-engineered blood vessels. J Clin Invest 2005; 115: 1816-1827.
16. Kim HY. Neuroprotection by docosahexaenoic acid in brain injury. Mil Med 2014; 179: 106-111.

17. Lai YC, Chen YM, Watkins SC, Nathaniel PD, Guo FL, Kochanek PK, Jenkins LW, Szabó C, Clark RSB. Identification of poly-ADP-ribosylated mitochondrial proteins after traumatic brain injury. J Neurochem 2008; 104: 1700-1711.

18. Lampugnani MG, Orsenigo F, Gagliani MC, Tacchetti C, Dejana E. Vascular endothelial cadherin controls VEGFR-2 internalization and signaling from intracellular compartments. J Cell Biol 2006; 174: 593-604

19. Lambert C, Cisternas P, Inestrosa NC. Role of Wnt signaling in central nervous system injury. Mol Neurobiol 2016; 53: 2297 2311.

20. Lafuente JV, Argandona EG, Mitre B. VEGFR-2 expression in brain injury: its distribution related to brain-blood barrier markers. J Neural Transm 2006; 113: 487-496.

21. Leng Y, Wang Z, Tsai LK, Leeds P, Fessler EB, Wang J, Chuang DM. FGF-21, a novel metabolic regulator, has a robust neuroprotective role and is markedly elevated in neurons by mood stabilizers. Mol Psychiatry 2015; 20: 215-223.

22. Li A, Sun X, Ni Y, Chen X, Guo A. HIF-1a involves in neuronal apoptosis after traumatic brain injury in adult rats. J Mol Neurosci 2013; 51: 1052-1062.

23. Livak KJ, Schmittgen TD. Analysis of relative gene expression data using real-time quantitative PCR and the 2(-Delta Delta $C(T))$ method. Methods 2001; 25: 402-408.

24. Lundblad C, Bentzer P. Effects of L-arginine on cerebral blood flow, microvascular permeability, number of perfused capillaries, and brain water content in the traumatized mouse brain. Microvasc Res 2007; 74: 1-8.

25. Meffre D, Grenier J, Bernard S, Courtin F, Dudev T, Shackleford G, Jafarian-Tehrani M, Massaad C. Wht and lithium: a common destiny in the therapy of nervous system pathologies? Cell Mol Life Sci 2014; 71: 1123-1148.

26. Mills JD, Bailes JE, Sedney CL, Hutchins H, Sears B. Omega-3 fatty acid supplementation and reduction of traumatic axonal injury in a rodent head injury model. J Neurosurg 2011; 114: 77-84.

27. Moncada S, Palmer RM, Higgs EA. Nitric oxide: physiology, pathophysiology, and pharmacology. Pharmacol Rev 1991; 43: 109-142.

28. Murohara T, Asahara T, Silver M, Bauters C, Masuda H, Kalka C, Kearney M, Chen D, Symes JF, Fishman MC, Huang PL, Isner JM. Nitric oxide synthase modulates angiogenesis in response to tissue ischemia. J Clin Invest 1998; 101: 2567-2578.

29. Najem D, Rennie K, Ribecco-Lutkiewicz M, Ly D, Haukenfrers J, Liu Q, Nzau M, Fraser DD, Mahmud BY. Traumatic brain injury: classification, models, and markers. Biochem Cell Biol 2018; 96 : 391-406.

30. Nguewa PA, Fuertes MA, Valladares B, Alonso C, Perez JM. Poly(ADP-ribose) polymerases: homology, structural domains and functions. Novel therapeutical applications. Prog Biophys Mol Biol 2005; 88: 143-172.

31. Noshita N, Lewén A, Sugawara T, Chan PH. Akt phosphorylation and neuronal survival after traumatic brain injury in mice. Neurobiol Dis 2002; 9: 294-304. 
32. Oguro A, Fujita K, Ishihara Y, Yamamoto M, Yamazaki T. DHA and its metabolites have a protective role against methylmercury-induced neurotoxicity in mouse primary neuron and SH-SY5Y cells. Int J Mol Sci 2021; 22: 3213.

33. Oren M, Damalas A, Gottlieb T, Michael D, Taplick J, Leal JF, Maya R, Moas M, Seger R, Taya Y, Ben-Ze'Ev A. Regulation of p53: intricate loops and delicate balances. Ann N Y Acad Sci 2002; 973: 374-383.

34. Poitras MF, Koh DW, Yu SW, Andrabi SA, Mandir AS, Poirier GG, Dawson VL, Dawson TM. Spatial and functional relationship between poly(ADP-ribose) polymerase-1 and poly(ADP-ribose) glycohydrolase in the brain. Neuroscience 2007; 148: 198-211.

35. Riascos-Bernal DF, Chinnasamy P, Cao LL, Dunaway CM, Valenta T, Basler K, Sibinga NES. beta-Catenin C-terminal signals suppress $\mathrm{p} 53$ and are essential for artery formation. Nat Commun 2016; 7: 12389.

36. Schaible EV, Windschugl J, Bobkiewicz W, Kaburov Y, Dangel L, Kramer T, Huang CS, Sebastiani A, Luh C, Werner C, Engelhard K, Thal SC, Schäfer MKE. 2-Methoxyestradiol confers neuroprotection and inhibits a maladaptive HIF-1alpha response after traumatic brain injury in mice. J Neurochem 2014; 129: 940 954.

37. Strle K, Zhou JH, Shen WH, Broussard SR, Johnson RW, Freund GG, Dantzer R, Kelley KW. Interleukin-10 in the brain. Crit Rev Immunol 2001; 21: 427-449.

38. Wan C, Jiang J, Mao H, Cao J, Wu X, Cui G. Involvement of upregulated p53-induced death domain protein (PIDD) in neurona apoptosis after rat traumatic brain injury. J Mol Neurosci 2013; 51: 695-702.

39. Wei G, Dawson VL, Zweier JL. Role of neuronal and endothelial nitric oxide synthase in nitric oxide generation in the brain following cerebral ischemia. Biochim Biophys Acta 1999; 20: 23-23.

40. Wu D, Pan W. GSK3: a multifaceted kinase in Wnt signaling. Trends Biochem Sci 2010; 35: 161-168.

41. Xu H, Luo P, Zhao Y, Zhao M, Yang Y, Chen T, Huo K, Han H, Fei Z. Iduna protects HT22 cells from hydrogen peroxide-induced oxidative stress through interfering poly(ADP-ribose) polymerase-1-induced cell death (parthanatos). Cell Signal 2013; 25: 1018-1026.

42. Zhao S, Fu J, Liu X, Wang T, Zhang J, Zhao Y. Activation of Akt/ GSK-3beta/betacatenin signaling pathway is involved in survival of neurons after traumatic brain injury in rats. Neurol Res 2012; 34: 400-407.

43. Zhu W, Chi N, Zou P, Chen H, Tang G, Zhao W. Effect of docosahexaenoic acid on traumatic brain injury in rats. Exp Ther Med 2017; 14: 4411-4416.

44. Ziebell JM, Morganti-Kossmann MC. Involvement of pro- and anti-inflammatory cytokines and chemokines in the pathophysiology of traumatic brain injury. Neurotherapeutics 2010 7: 22-30. 